\title{
Arterial Occlusion in the Lower Leg
}

\author{
J. KENNEDY WATT,* M.B., CH.M., B.SC., F.R.C.S., F.R.C.S.GLAS.
}

Brit. med. F., 1966, 1, 18-20

When aortography is employed in the investigation of patients with arterial occlusion of the lower limb satisfactory visualization of the arterial tree to the level of the popliteal bifurcation or beyond is possible. However, even when a satisfactory aortographic technique is available and detailed examination of the tibial arteries is possible it is customary to $x$-ray only those patients whose lesions may be suitable for surgery. Comprehensive studies of lower-leg occlusion are therefore uncommon, and have been undertaken in limbs amputated for gangrene (Dible, 1956) or have evoked comment only in so far as they affect the assessment of femoro-popliteal occlusions in patients with gangrene (Taylor, 1962).

In the present study a comprehensive group of 264 men with intermittent claudication ( $85 \%$ of those presenting in a given period at the out-patient department) was investigated by bilateral femoral arteriography (Watt, 1965). Patients with aorto-iliac occlusion were excluded from the study as bilateral femoral arteriography is usually inapplicable, and, from observation, the incidence of lower-leg occlusion in these patients is low. With this method adequate visualization of the tibial arteries to the level of the ankle was obtained, and it has been possible to analyse the pattern of arterial occlusion in the lower leg.

\section{Results}

Of the 528 arteriograms (264 patients) 74 (14\%) showed no evidence of occlusion or severe narrowing in the thigh or lower leg (these are the arteriograms of those patients with unilateral occlusion who had no lesion in the symptomless leg); $213(40.3 \%)$ showed a femoro-popliteal occlusion or gross narrowing of the femoro-popliteal segment, without lowerleg occlusion; $167(31.6 \%)$ showed a femoro-popliteal lesion (occlusion or severe narrowing) with associated lower-leg occlusion; and $74(14 \%)$ showed lower-leg occlusion only. That is, $241(45.6 \%)$ of the arteriograms showed occlusion of one or more lower-leg arteries.

The seven combinations of lower-leg occlusions are shown in Table I. It will be seen that the commonest lesion is an

Table I.-Occlusion of the Tibial and Peroneal Arteries

\begin{tabular}{|c|c|c|c|c|}
\hline $\begin{array}{l}\text { Type of } \\
\text { Occlusion }\end{array}$ & & $\begin{array}{l}\text { No. of } \\
\text { Occlusions }\end{array}$ & $\begin{array}{c}\% \text { of } \\
\text { Lower-leg } \\
\text { Occlusions }\end{array}$ & $\begin{array}{l}\text { Incidence } \\
\text { in Series } \\
(\% \text { of } 528)\end{array}$ \\
\hline $\begin{array}{l}\text { Posterior tibial } \ldots \\
\text { Anterior } " \quad \cdots \\
\text { Peroneal } \\
\text { Ant./post. tibial } \\
\text { Post. tib./peroneal } \\
\text { Ant. tib./peroneal } \\
\text { A.T./P.T./peroneal }\end{array}$ & $\begin{array}{l}\cdots \\
\cdots \\
\cdots \\
\cdots \\
\therefore\end{array}$ & $\begin{array}{r}97 \\
54 \\
7 \\
46 \\
22 \\
3 \\
12\end{array}$ & $\begin{array}{r}40 \cdot 2 \\
22 \cdot 4 \\
2 \cdot 9 \\
19 \cdot 1 \\
9 \cdot 1 \\
1 \cdot 2 \\
5 \cdot 0\end{array}$ & $\begin{array}{r}18 \cdot 4 \\
10 \cdot 2 \\
1 \cdot 3 \\
8 \cdot 7 \\
4 \cdot 1 \\
0 \cdot 6 \\
2 \cdot 3\end{array}$ \\
\hline Total . . & $\ldots$ & 241 & $99 \cdot 9$ & $45 \cdot 6$ \\
\hline
\end{tabular}

isolated occlusion of the posterior tibial artery but that isolated anterior tibial occlusions and combined anterior tibial and posterior tibial occlusions are also common.

When only one artery is occluded the relative incidence of occlusion in the posterior tibial, anterior tibial, and peroneal arteries is $97: 54: 7$ (approximately $14: 8: 1$ ). When occlusions \footnotetext{
* Consultant Surgeon, Glasgow Royal Infirmary and Peripheral Vascular
Unit, Belvidere Hospital.
}

occurring alone or in combination are considered the relative incidence becomes posterior tibial:anterior tibial: peroneal as $177: 115: 44$ (approximately $4: 2.5: 1$ ). This is in accord with the relative frequency recorded by Lindbom (1950)-8:4:1.

\section{Occlusions of the Posterior Tibial Artery}

Current anatomical nomenclature is confusing in that the peroneal artery is described as a branch of the posterior tibial artery, whereas frequently it is the larger of the two arteries and is often the direct continuation of the main trunk. Henry (1945) prefers the French nomenclature, which describes a "tibio-peroneal trunk" and a "tibio-peroneal fork" giving origin to the posterior tibial and peroneal arteries. This terminology is unfamiliar, and in this article the proximal segment of the posterior tibial artery is described as the "posterior tibial stem" which gives rise to the posterior tibial and peroneal arteries at the "posterior tibial bifurcation."

Variations in the pattern of posterior tibial occlusions are numerous, but it has been possible to classify the 177 occlusions in 11 patterns (see Chart). The commonest finding was occlusion of the whole length of the posterior tibial artery-81 arteriograms. Irregularity of outline of the stem was a feature of many arteriograms. Twenty showed an isolated stem occlusion, and in 19 others the stem and posterior tibial artery were occluded from the popliteal bifurcation to the ankle.

Reconstruction of the distal segment of the posterior tibial artery through the malleolar anastomosis with the peroneal

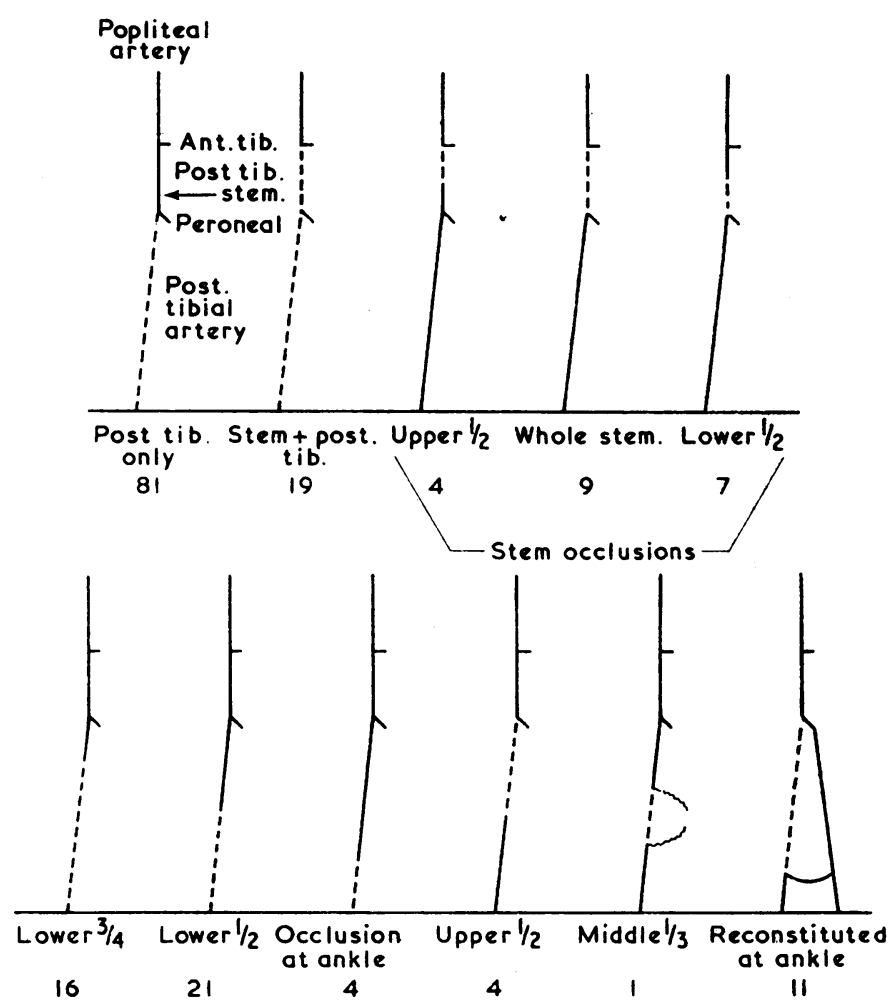

Diagram showing variations in the pattern of posterior tibial occlusions. 
artery was a feature in 11 cases, but normally the collateral vessels arising from the lower-leg arteries are small or are narrowed at their origin and there is a tendency for occlusion to become complete.

\section{Occlusions of the Anterior Tibial Artery}

Anterior tibial occlusion is less common than occlusion of the posterior tibial artery, either as the solitary lower-leg occlusion (A.T.:P.T.: :54:97) or with regard to the total number of occlusions (A.T.:P.T.: :115:177)-Table I. It was frequently bilateral, being present in 10 patients as the only lesion and in 21 patients as a combined lesion-that is, bilateral anterior tibial occlusion accounted for $62(53.9 \%)$ of the 115 occlusions.

In many cases the artery is patent in the proximal segment and is occluded beyond. Although the image of the proximal portion of the artery is foreshortened in its course to the front of the leg, measurement on film of the distance between the popliteal bifurcation and the upper end of the occlusion was undertaken (Table II). This shows that occlusion was total in 39 cases, and these occlusions probably originated from atheromatous lesions of the popliteal bifurcation. In the majority the artery was occluded after a short course of $1-5 \mathrm{~cm}$. (on film), which suggests an association between the development of occlusion and the upper border of the interosseous membrane similar to the relationship of the superficial femoral artery to the adductor tendon.

TABle II.-Occlusions of the Anterior Tibial Artery-Length of Patent Vessel Measured on Film from the Origin

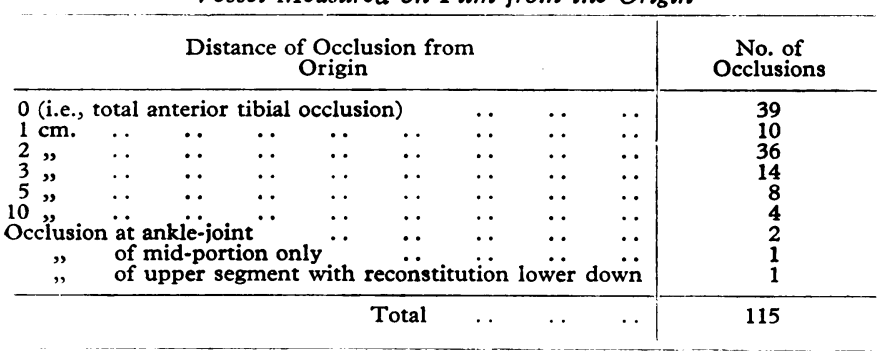

\section{Occlusions of the Peroneal Artery}

Occlusion of this artery was found in 44 arteriograms (Table I), but in only 7 did it occur as the solitary lower-leg occlusion.

In the majority (34) there was also an occlusion of the posterior tibial artery, and it is probable that peroneal occlusion is secondary to occlusion of the posterior tibial artery or to occlusion of its origin caused by plaque formation at the posterior tibial bifurcation.

\section{Incidence of Lower-leg Occlusion in Different Age Groups}

In the 264 patients with intermittent claudication symptoms were unilateral in 184 (94 right leg; 90 left leg) and bilateral in 80. The age distribution of these patients was very similar to that found by Taylor and Calo (1962). When the patients were grouped as 54 years or younger, 55-64 years, and 65 years or older, three groups of reasonable size were obtained.

TABLE III.-Incidence of Tibial Occlusion in the Claudicating Leg of 184 Patients with Unilateral Claudication Analysed with Respect to Age

\begin{tabular}{c|c|c|c}
$\begin{array}{c}\text { Age Group } \\
\text { (Years) }\end{array}$ & $\begin{array}{c}\text { No. in } \\
\text { Group }\end{array}$ & $\begin{array}{c}\text { Tibial Occlusions } \\
\text { No. of }\end{array}$ & $\begin{array}{c}\text { Incidence } \\
(\%)\end{array}$ \\
\hline $\begin{array}{c}54 \\
55-64\end{array}$ & 51 & 13 & 25.5 \\
$65+$ & 91 & 35 & 38.5 \\
\hline Total & 42 & 29 & 69.0 \\
\hline
\end{tabular}

The incidence of lower-leg occlusion was analysed for the claudicating leg of the 184 patients with unilateral claudication (Table III), and a steep rise was found from $25.5 \%$ in those up to 54 years of age to $69 \%$ in patients aged 65 and over.

A similar rise in the incidence of tibial occlusions with age was evident in the 80 patients with bilateral claudication (Table IV). In these patients the incidence is higher at all ages than in unilateral claudication, and in the elderly group lower-leg occlusion was present in $80.6 \%$ of the 36 arteriograms. Only three of these 18 patients had no lower-leg occlusion in either leg.

TABLE IV.-Incidence of Tibial Occlusion in 80 Patients with Bilateral Claudication Analysed with Respect to Age

\begin{tabular}{c|c|c|c|c}
$\begin{array}{c}\text { Age Group } \\
\text { (Years) }\end{array}$ & $\begin{array}{c}\text { No. in } \\
\text { Group }\end{array}$ & $\begin{array}{c}\text { No. of } \\
\text { Legs }\end{array}$ & $\begin{array}{c}\text { No. of Tibial } \\
\text { Occlusions }\end{array}$ & $\begin{array}{c}\text { Incidence } \\
(\%)\end{array}$ \\
\hline 54 & 24 & 48 & 22 & $48 \cdot 8$ \\
$55-64$ & 38 & 76 & 37 & $48 \cdot 7$ \\
$65+$ & 18 & 36 & 29 & $80 \cdot 6$ \\
\hline Total & 80 & 160 & 88 & 55
\end{tabular}

\section{Discussion}

This analysis of lower-leg occlusion in intermittent claudication shows that tibial and/or peroneal occlusion, occurring alone or in combination with femoro-popliteal occlusion, is common in patients with intermittent claudication and has a high incidence in the elderly patient.

It is noteworthy that none of these claudicating patients had a femoro-popliteal occlusion together with occlusion of all three lower-leg arteries, and an adequate " run-off " would have been available after surgery in all cases. However, the high incidence of lower-leg occlusion indicates that the selection of patients for femoro-popliteal surgery should include assessment of possible lower-leg lesions. Bilateral studies are important, as it was found that 76 of the 184 patients with unilateral claudication had a lower-leg occlusion in the symptomless leg, an incidence which was as high as that in the claudicating leg $(77 / 184)$.

In 71 patients two lower-leg arteries were occluded (Table I), and the remaining artery was the only main channel through which blood was supplied to the foot. Where only one artery remained patent the incidence of sole patency was-peroneal: anterior tibial: posterior tibial: : 46:22:3. In his dissections of limbs amputated for gangrene Dible (1956) found that the peroneal artery was the only patent vessel in $28 \%$ of limbs-a feature he named "peroneal leg." In the present series peroneal leg occurred in $8.7 \%(46 / 528)$, indicating a lower incidence of this finding in claudicating patients.

The low incidence of sole patency of the posterior tibial artery (three cases) (Table I) is a further indication that this artery is more severely affected by atherosclerosis than the other two.

From Table I we find that $54.4 \%$ of arteriograms showed no lower-leg occlusion; $29.9 \%$ had one occluded artery ; $13.4 \%$ had two occluded; and only $2.3 \%$ had occlusion of all three arteries. Comparable figures are rare, but Linton and Darling (1962) reported occlusion of two lower-leg vessels in $22 \%$ of 76 patients operated on for intermittent claudication, and Taylor (1962) in 51 patients operated on for gangrene found that $24 \%$ had no tibial occlusion, $35 \%$ had occlusion of two arteries, and $41 \%$ had occlusion of all three lower-leg arteries in some part of their course. The high incidence of tibial occlusion in these patients with gangrene compared with the present series is indicative of the severe changes associated with tissue necrosis.

\section{Summary}

An analysis of the incidence of lower-leg occlusion in 264 patients with intermittent claudication undergoing bilateral femoral arteriography is presented. 
Occlusion of the posterior tibial artery is the commonest lesion and isolated anterior tibial and combined anterior and posterior tibial occlusions are also common. The peroneal artery is rarely occluded as the sole lower-leg lesion.

The incidence of lower-leg occlusion is high (45.6\%) and rises steeply with increasing age.

I wish to express my grateful thanks to my colleagues, Mr. W. Reid and Mr. T. G. Gray, for permission to include their patients in this survey, and to Dr. D. Raeside for the skill that made it possible to obtain the excellent arteriograms on which this article is based.

REPERENCES

Dible, J. H. (1956). In Peripheral Vascular Disorders, edited by P. Martin, R. B. Lynn, J. H. Dible, and I. Aird. Livingstone, Edinburgh and London.

Henry, A. K. (1945). Extensile Exposure Applied to Limb Surgery. Livingstone, Edinburgh

Lindbom, A. (1950). Acta radiol. (Stockh.), suppl. No. 80.

Linton, R. R., and Darling, R. C. (1962). Surgery, 51, 62.

Taylor, G. W. (1962). Ann. roy. Coll. Surg. Engl., 31, 168.

Taylor, G. W. (1962). Ann. roy. Coll. Surg. Engl.,

Watt, J. Kennedy (1965). Ibid., 2, 1455.

\title{
Haemoglobin Estimation : a Comparison of Different Techniques
}

\author{
P. C. ELWOOD,* M.D., D.P.H., D.C.H. ; A. JACOBS, $†$ M.D., M.C.PATH.
}

Brit. med. F., 1966, 1, 20-24

This trial was undertaken to try to assess the relative usefulness of different types of apparatus recommended for haemoglobin estimation. With the exception of the E.E.L. colorimeter all the equipment used was specifically designed for haemoglobinometry. The errors of four observers of varied experience were examined by means of seven different techniques, and the consistency of their errors was assessed at different haemoglobin levels. In addition, the general convenience and acceptability of each method was noted.

Recent statements (Brit. med. F., 1965), made with no supporting evidence, have condemned the use of whole-blood methods of haemoglobinometry and instruments employing visual matching. The present trial shows that such general statements are not fully justified and that a method in which whole blood is used may be fully adequate for some purposes and compare well with a method using a photoelectric colorimeter. The Tallqvist method was included in this investigation only because it is known to be still used by some doctors. The results it gave were too erratic for analysis.

\section{Types of Apparatus Used in the Trial}

E.E.L. Haemoglobin Meter (made and distributed by Evans Electroselenium Ltd.).-Diluted blood in a matched colorimeter tube is place in the instrument. Transmitted green light from a mains-lit bulb is measured photoelectrically. The haemoglobin concentration is indicated by the deflection of a galvanometer as $\mathrm{g} . / 100 \mathrm{ml}$. of blood or as percentage haemoglobin (based on $100 \%=14.6 \mathrm{~g}$. $\mathrm{Hb}$ ). Oxyhaemoglobin or cyanmethaemoglobin can be estimated. For either estimation two standards are required-one high $(18 \mathrm{~g} . / 100 \mathrm{ml}$.) and one low (3 g./ $100 \mathrm{ml}$.) - and, while these can be obtained ready for use with the cyanmethaemoglobin method, they have to be freshly prepared each day for the oxyhaemoglobin method. For preparation of the oxyhaemoglobin standards lysed whole-blood standards are available with a table giving the required dilutions (stated to the nearest $0.05 \mathrm{ml}$.). The instrument is slow to stabilize when switched on (15 minutes is recommended) but appears to be very stable thereafter. Standardization is tedious for the oxyhaemoglobin method, and during the preparation of the standards considerable errors may occur. The instrument is very convenient to use, particularly as it is direct-

- M.R.C. Epidemiological Research Unit, Cardiff.

† Department of Pathology, Welsh National School of Medicine, Cardiff reading. It is not readily portable, and diluting fluid, pipettes, and standards are required for its use.

E.E.L. Colorimeter (made and distributed by Evans Electroselenium Ltd.). - Diluted blood is placed in a matched colorimeter tube. Transmitted green light from a mains-lit bulb is measured photoelectrically and read on a galvanometer in arbitrary units. The zero is set on a tube filled with diluent, and any haemoglobin derivative (oxyhaemoglobin, cyanmethaemoglobin, etc.) can be estimated, provided a calibration curve is prepared with serial dilution of a standard blood of known haemoglobin level. The initial calibration is tedious, but otherwise the instrument is easy to use. It requires very frequent readjustments of the zero, but this is very simply done. It also requires regular checking of the calibration curve with a blood of known haemoglobin level. Occasional recalibration may be necessary. It is not easily portable, and diluting fluid and pipettes are required for its use.

Keeler Haemoscope (made and distributed by C. Davis Keeler Ltd.).-This instrument is a development of the M.R.C. grey-wedge photometer and it was tested in prototype form. A diluted sample of blood is placed in a square cell. The intensity of transmitted green light from a battery-lit bulb is viewed through an eyepiece and compared on a split screen with that of a variable standard. Haemoglobin levels are given in $\mathrm{g} . / 100 \mathrm{ml}$. of blood. There are separate scales for oxyhaemoglobin and cyanmethaemoglobin. A neutral glass standard is supplied with the instrument, and any difference between its nominal and estimated value can be used to correct subsequent readings. This instrument is quick and simple to use, but matching of the sample and standard is not easy. The use of the neutral glass standard to correct readings seems to be of doubtful value. It is robustly made and well finished, and is easily portable, but diluting fluid and pipettes are required.

Zeiss Hämometer (this instrument was made by Zeiss but is no longer available).-Blood is diluted with $0.1 \mathrm{~N}$ hydrochloric acid in a special mixing pipette and placed in a square colorimeter tube. Five minutes after mixing the colour density of the sample in reflected daylight is viewed through an eyepiece and matched with that of a variable standard seen on a split screen. The colour intensity of the standard is varied, and when matched with the sample indicates haemoglobin concentration in $\mathrm{g} . / 100 \mathrm{ml}$. of blood. This instrument is quite convenient to use ; but it is slow, and matching of the sample and standard is difficult. No method of standardization is supplied. It is easily portable, but diluting fluid is required. 